\title{
Microstructure Devices for Water Evaporation
}

\author{
Eugen ANURJEW ${ }^{1}$, Edgar HANSJOSTEN ${ }^{1}$, Stefan MAIKOWSKE ${ }^{1}$, \\ Ulrich SCHYGULLA ${ }^{1}$ and Juergen J. BRANDNER ${ }^{1, *}$ \\ * Corresponding author: Tel.: ++49 (0)7247 823963; Fax: ++49 (0)7247 823186; \\ Email: Juergen.brandner@imvt.fzk.de \\ 1: Institute for Micro Process Engineering, Forschungszentrum Karlsruhe, Germany
}

\begin{abstract}
Evaporation of liquids is of major interest for many topics in process engineering. One of these is chemical process engineering, where evaporation of liquids and generation of superheated steam is mandatory for numerous processes. Generally, this is performed by use of classical pool boiling and evaporation process equipment, providing relatively limited performance, or by other systems like fallingfilm evaporators. Due to the advantages of microstructure devices especially in chemical process engineering the interest in microstructure evaporators and steam generators have been increased through the last decade. In this publication different microstructure devices used for evaporation and generation of steam will be described. Starting with simple liquid-heated devices, different types of electrically powered devices containing micro channels as well as non-channel microstructures will be shown. While evaporation of liquids in crossflow and counterflow or co-current flow micro channel devices is possible, it is, in many cases, not possible to obtain superheated steam due to certain boundary conditions. Thus, a new design was proposed to obtain complete evaporation and superheating of the generated steam.
\end{abstract}

Keywords: Evaporation, Microstructures, Visualization, Superheating

\section{Introduction}

Microstructured devices have become increasingly important in thermal and chemical process engineering within the last years. These devices are often made out of micro structured metal foils, which are connected by diffusion bonding $[1,2]$. The hydraulic diameters of the micro channels, generated by precision machining or wet chemical etching, are in the range of a few hundred micrometres.

Metallic microstructured devices provide high pressure resistance and small residual volumes. Due to the size of the microstructures they act as flame arresters or explosion barriers; thus they are well suited to handle dangerous or explosive fluids (see e.g. [3, 4]). The small dimensions of micro channels enable very high surface-to-volume ratios up to $30000 \mathrm{~m}^{2} \cdot \mathrm{m}^{-3}$, which are about one or two orders of magnitude higher than those of conventional process engineering equipment devices. This high surface-to-volume ratio leads to increased heat transfer, the micro dimensions of the channels to short diffusion lengths [1, 5]. Therefore, microstructured devices are well suited for operations dealing with high heat fluxes and rapid mass transfer like evaporation.

Phase transition and multiphase flow in macro channels have been intensively investigated and are well known and understood. In micro channels, phase transition, related phenomena and multiphase flow have been partially investigated [6]. Most results presented so far have been obtained with single micro channels, sometimes multimicro channel arrays have been investigated for their behaviour in evaporation. However, results about the phenomena occurring in multi micro channel arrays are often not consistent, depending on the experimental setup, the fluid looked at and the measurement methods.

\section{Metallic Multi-Micro channel Devices}

First attempts to evaporate water have been done using micro channel heat exchangers in 
crossflow design. Manufacturing of these devices was described before in details [1, 2, 3]. Fig. 1 shows different examples for microstructure foils integrated into crossflow heat exchangers made of stainless steel, shown in Fig. 2. A stainless steel counterflow heat exchanger is shown in Fig. 3.
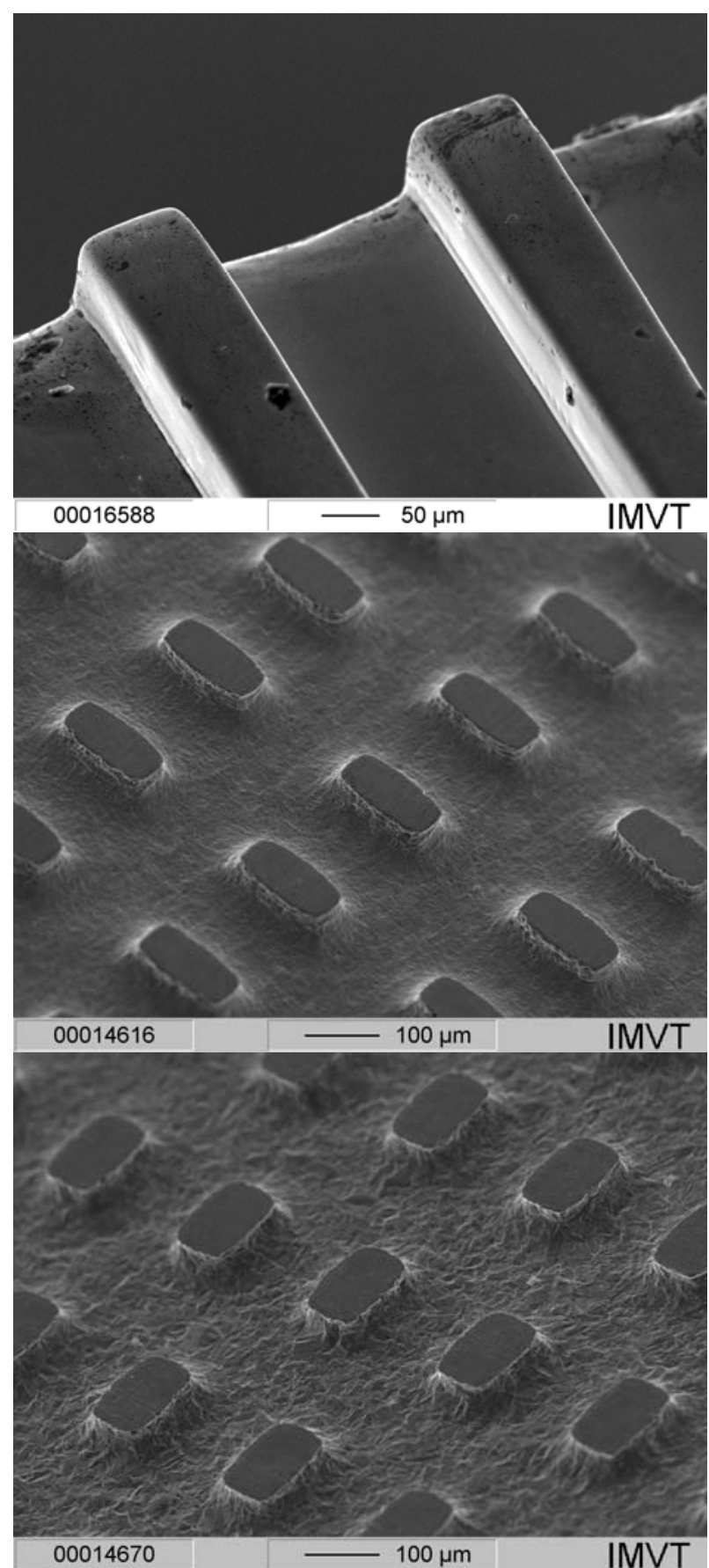

Fig. 1: Stainless steel microstructure foils to be integrated into crossflow heat exchanger devices.

Several experiments with crossflow devices showed that evaporation of water is possible, using hot thermo oil in the heating passage of the device. However, wet steam was generated containing very high percentage of droplets, and no superheating could be obtained. This was, at least partly, due to short residence time of the fluid and limited temperature of the heating side. Thus, electrically powered micro heat exchangers have been developed, manufactured and tested to provide higher temperatures with good controllability of the power supplied [7, 8]. Fig. 4 shows three different sizes of electrically powered micro heat exchangers.

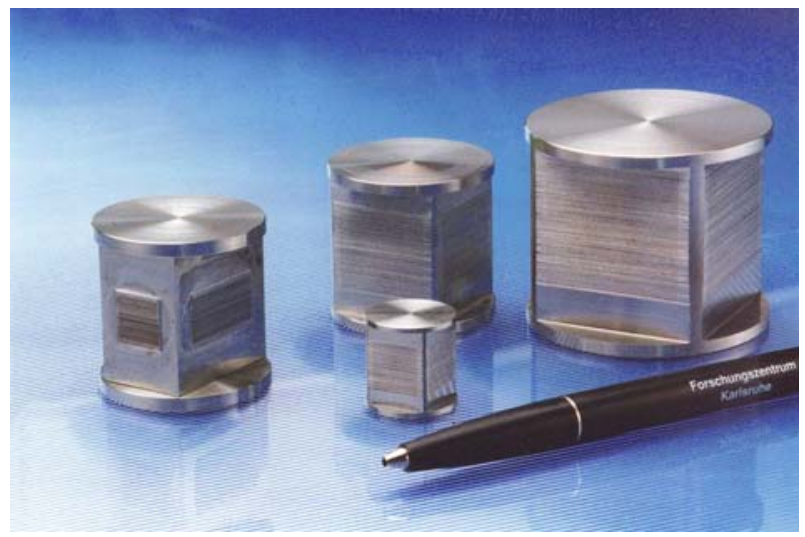

Fig. 2: Stainless steel crossflow micro heat exchangers of different size. For technical details see $[1,3,5]$.

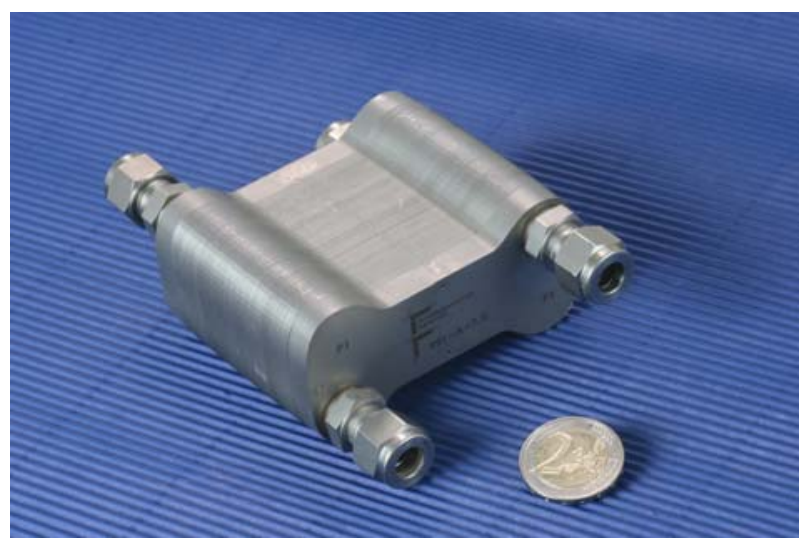

Fig. 3: Stainless steel counter-current flow microstructure heat exchanger. For technical details see $[1,5]$.

With these devices, not only straight rectangular micro channels but also semielliptic micro channels in convoluted or sinusoidal arrangements have been tested for evaporation. It could be shown that, depending on the applied mass flow, either a single 
microstructure device or a two-stagearrangement, which means two devices in a row, can be used for complete evaporation and superheating of water and other liquids [9].

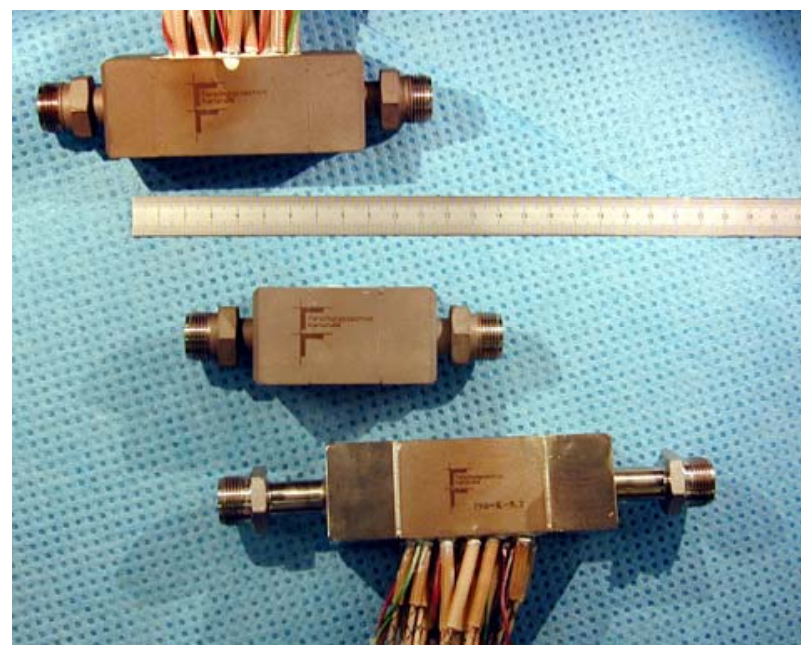

Fig. 4: Electrically powered microstructure heat exchangers of different size. Technical details can be obtained from $[1,7,8]$.

Substantial data on the droplet content contained in the vapour flow could be obtained by a simple photometer setup. A photo current was measured, obtained by scattered laser light in full reflection from the vapour outlet of different arrangements of electrically powered devices. The amplitude of photo current could directly be correlated to the droplet content of the vapour as well as to the vapour temperature $[1,10]$.

\section{Multi-Micro channel Device for Vizualisation of Evaporation}

Although evaporation of liquids can be performed successfully using devices like those described in section 2, it was still not quite clear which parameters strongly influence the evaporation process inside a multi-micro channel system. Numerous research activities have been done to clarify the evaporation processes taking place in single micro channels (see e.g. [11 - 15]), but not so many research activities have been dedicated to multi-micro channel array evaporators.

An electrically powered stainless steel frame was manufactured to allow the exchange of micro channel structures as well as the optical inspection of the processes inside the micro channels using high speed videography. More details of the design as well as of an improved device can be found in [1] and will be given in another publication in close future. Fig. 5 shows a photo of the device.

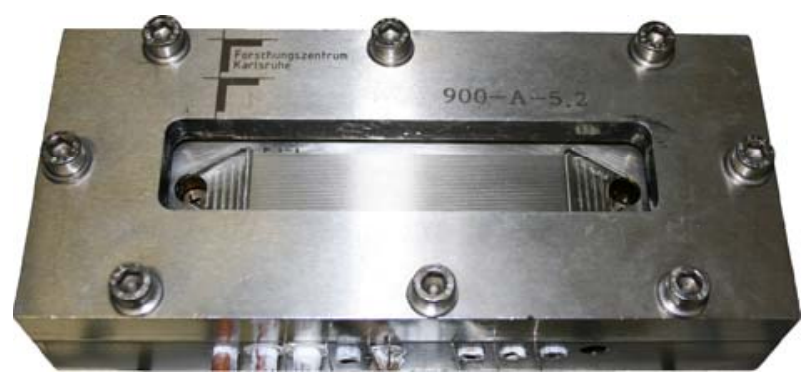

Fig. 5: Electrically powered microstructure device, providing exchangeable micro channel foils and a glass lid for high speed videography.

The apparatus design provides the possibility to vary different parameters like temperature, applied electrical power, volume flow rate or pressure drop. Additionally, microstructured metal foils -including multimicro channel arrays- are exchangeable. Thus, phase transition and multiphase flow in several kinds of different micro channel geometries and arrangements could be investigated.

The method of visualization by high speed videography has been applied to perform initial investigations on phase transition as well as on the dynamics of gas-liquid flows in narrow channels $[11,16]$. The experimental setup used here contains a microscope in combination with a digital high-speed camera. The microscope is arranged above the horizontal multi-micro channel layer. The digital high-speed camera records pictures at frequencies of up to 200000 frames per second with very low motion blur. Special computational algorithms can be used to analyse these recorded high-speed picture sequences to extract information about different phases.

\subsection{Phase transition phenomena}

Phase transition in micro channels is accompanied by several phenomena like 
vapour plugging or vapour slugging, which occur only to a minor extent or are not available in macro channels. Two different types of vapour plugging were observed vapour plugging at channel inlets and vapour plugging inside of micro channels. All these observations of evaporation were performed with liquid water and related steam in micro channels with rectangular cross-sections in the range of about $200 \mu \mathrm{m}$ (width) and $100 \mu \mathrm{m}$ (depth).

Vapour plugging at channel inlets occurs when existing vapour bubbles, which have been generated by boiling inside the inlet void, agglomerate at channel entrances. These bubbles are temporarily fixed and expand by capturing small bubbles. The fixed bubbles can partially be discharged by micro channels when a specific bubble size is reached. Consequently, channel entrances are temporarily plugged by bubbles. Fig. 6 shows a picture sequence of plugged channel entrances. Gas fractions inside of these channel inlets (indicated in the right picture of Fig. 6.) indicate bubble drainages by micro channels.

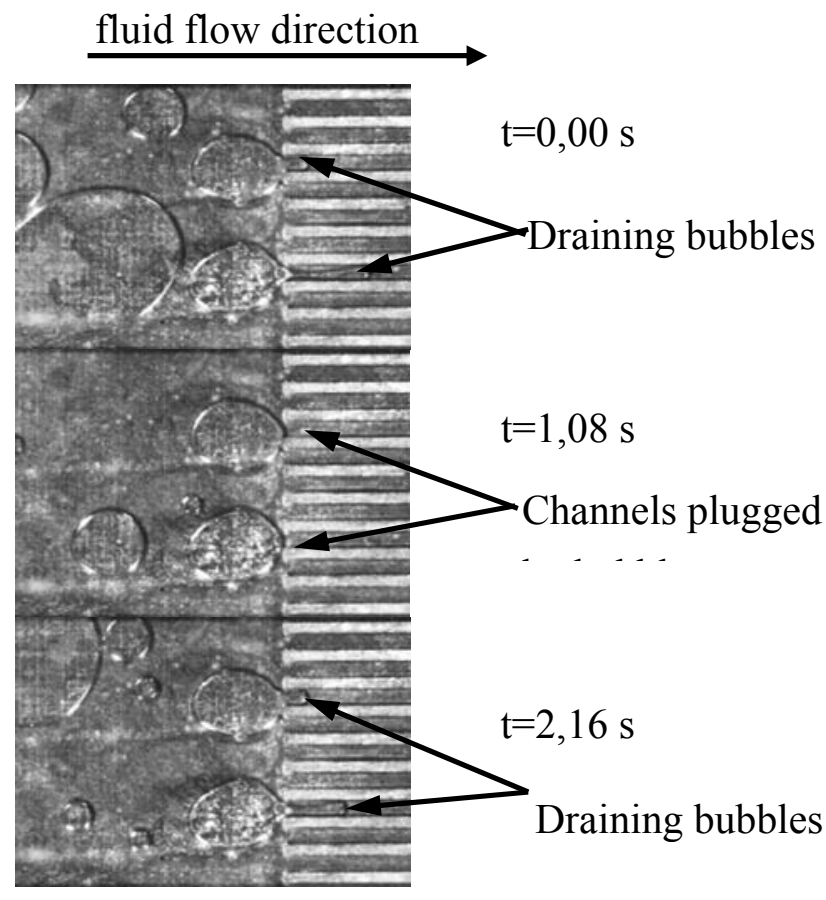

Fig. 6. Vapour plugging at channel inlets, $100^{\circ} \mathrm{C}$, the multi-micro channel array is located on the right side

Another type of vapour plugging is the plugging inside micro channels. Rapidly growing bubbles are accompanied by accelerated bubble-endings and decelerated bubble-beginnings. If the motion of a bubble beginning stops due to the bubble-growing, the corresponding micro channel is temporarily plugged by vapour. Another effect of this channel-plugging is the reversal of flow direction of bubble beginnings caused by explosively growing bubbles. Fig. 7 shows a section of a multi-micro channel array at different time steps. Fluid flow direction is from left to right. The movement of bubble beginnings in both channels decreases continually until it stops. At this point $\left(\mathrm{t}=221 \cdot 10^{-3} \mathrm{~s}\right)$ both channels are temporarily plugged by stagnant bubble beginnings. Eventually, the bubble beginnings start moving in the opposite direction to the fluid flow and thereby transport liquid fluid backwards.

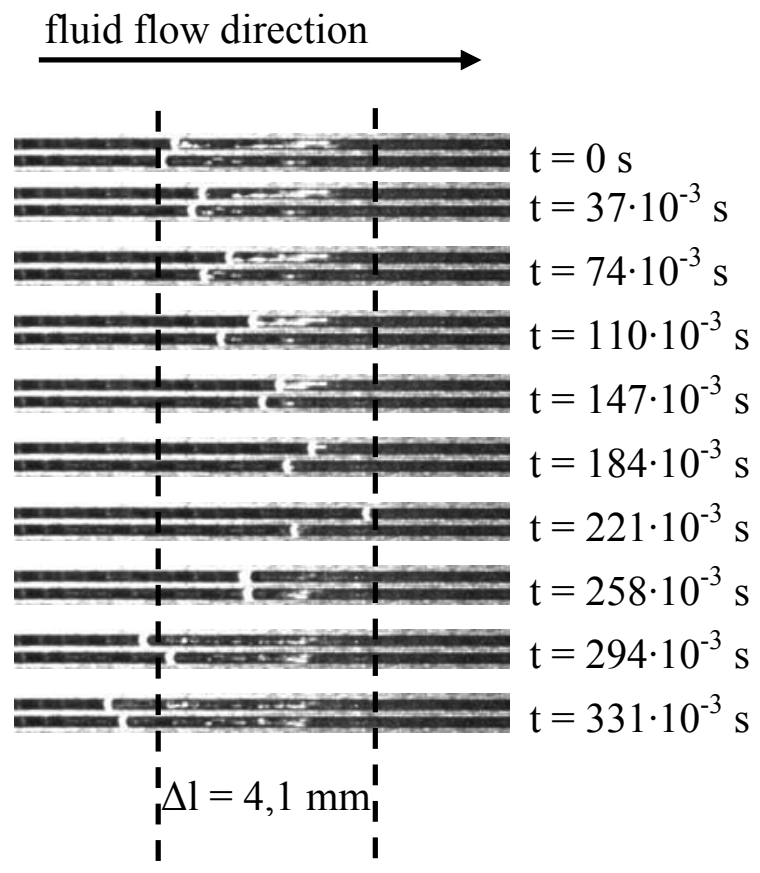

Fig. 7: Vapour plugging inside of micro channels, reversal of flow direction by rapidly growing bubbles, $150^{\circ} \mathrm{C}$.

Vapour slugging is also caused by rapidly growing bubbles. Liquid fractions, trapped between two bubbles, are slugged out of the micro channel by accelerated bubble-endings. The contact time between these liquid fractions and the heated micro channel wall is too low for a complete evaporation. 
The above mentioned phase transition phenomena lead to non-uniform fluid flow distribution in multi-micro channel arrays and result in non-uniform vapour quality at evaporator outlets. Controlling or reducing these phenomena results in a nearly constant phase transition inside of multi-micro channel arrays and in a related constant vapour quality at the evaporator outlet. Fig. 8 shows an example of such a nearly constant phase transition inside of a multi-micro channel array. The parabolic shape is probably caused by non-uniform fluid flow distribution at the channel entrances.

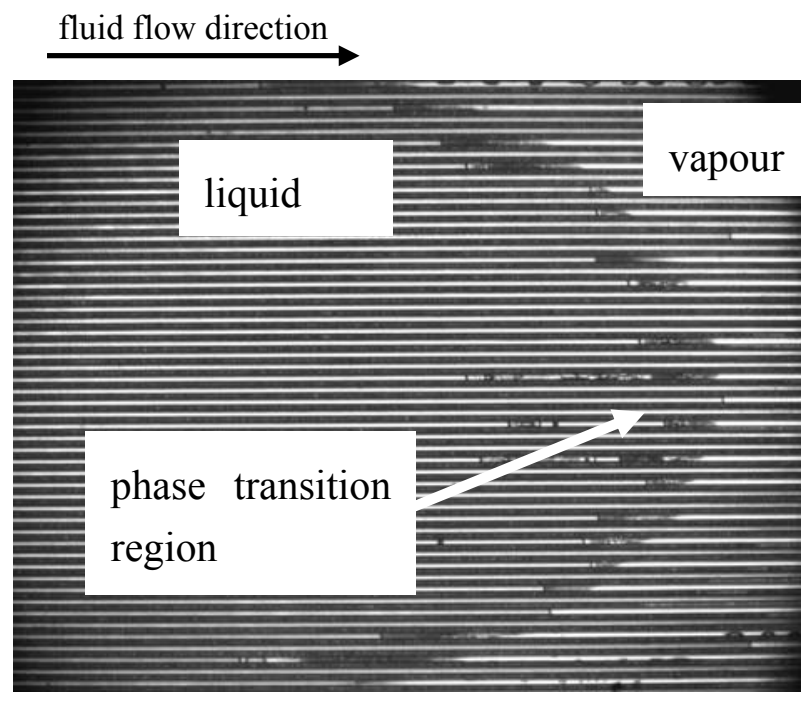

Fig. 7: Nearly constant phase transition inside of a multi-micro channel array at $130^{\circ} \mathrm{C}$

The parabolic shape might be avoided by use of a tree-like distribution system at the entrance of the multi-micro channel array to provide equal distribution of flow velocity to all micro channels and, therefore, an equal distribution of the residence time in the evaporation area. Fig. 8 shows a microstructure foil with conventional distribution system on the left side and a treelike distribution system on the right side. Flow direction can easily be changed with this foil.

The tree-like system was tested, and, as expected, the parabolic shape of the phase transition front could be drastically changed to a phase transition front more or less perpendicular to the streamline and the micro channel direction.

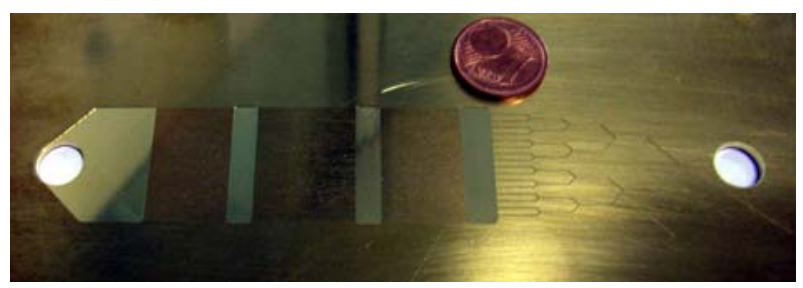

Fig. 8: Multi-micro channel foil providing a standard flow distribution void (left) and a tree-like distribution system (right). Evaporation takes place in a three-staged multi-micro channel array (center).

The tree-like structure is designed for branching of the flow into sub-flows providing the same hydrodynamic properties at any position in the distribution system. Aside of this, the micro-channel arrays are separated into three stages with connecting voids in between to allow evaporation and superheating.

\section{Evaporator Design with Circular Blanks}

Due to the strong increase in volume while the phase transition takes place evaporation in long straight micro channels is limited. This is based on thermodynamic considerations. It is, in many cases, possible to evaporate a liquid volume flow completely, but superheating is difficult. A flow velocity limit, depending on the temperature and the pressure inside the evaporation system, can be obtained [17]. This flow velocity limit provides information on the maximum volume flow which can be evaporated and superheated using straight micro channels.

It is, thus, useful to think about micro evaporator designs which are not limited by a flow velocity. One possibility is the use of concentric circular blanks. This new design consists of circular or elliptically shaped ring walls which are arranged concentrically around a feed hole. Each of the ring walls show two overflow openings, which act as expansion nozzles. The position of those overflow openings is changed by $180^{\circ}$ from each ring to the next. Fig. 9 shows two examples of such microstructures, each generated on a round plate with $1.7 \mathrm{~cm}$ diameter. The first devices have been 
manufactured from a polymer by microstereolithography $[1,2,18]$, later devices have been manufactured by precision micromachining from copper to obtain higher steam temperatures.

The experiments have been performed using a metallic adapter system to house the circular blank arrangements. Water inlet and steam outlet as well as electric heaters and sensors have been integrated into the adapter system, which is shown in Fig. 10. Water mass flow was varied between $0.3 \mathrm{~kg} \cdot \mathrm{h}^{-1}$ and $1.0 \mathrm{~kg} \cdot \mathrm{h}^{-1}$, and evaporation was performed with ambient outlet pressure. The electrical heating power applied was varied according to this mass flow range to obtain full evaporation and superheating. A heating surface temperature limit of $170^{\circ} \mathrm{C}$ was randomly set, resulting in an applied electrical power of about $820 \mathrm{~W}$ and a evaporation power of $600 \mathrm{~W}$ for the maximum mass flow.

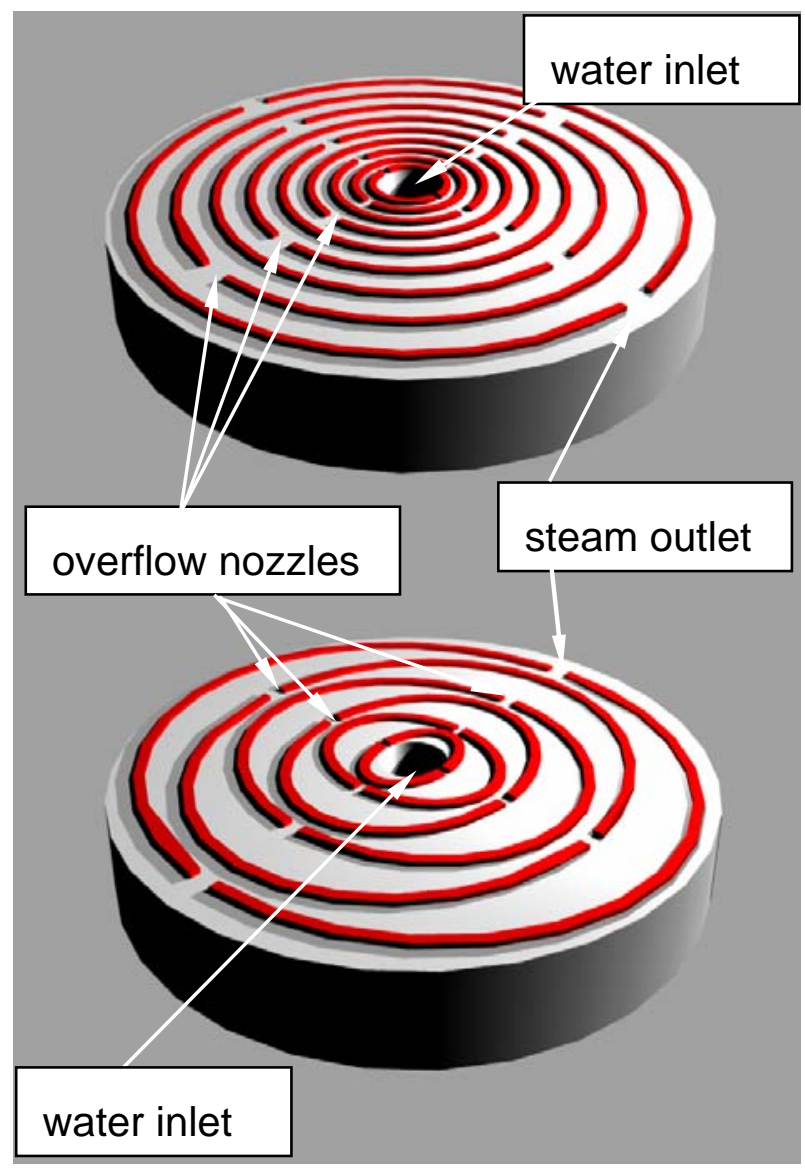

Fig. 9: Examples for circular blank arrangements used for water evaporation.
A brief summary of experimental parameters is given in table 1 . The differences between applied electrical power and evaporation power are heat losses as well as the power consumed for superheating. It was, at least in the existing experimental setup, not possible to determine the heat losses exactly. However, the power applied for superheating can be neglected in comparison to what is needed for evaporation, thus the most of the difference is most likely heat losses.

Numerous designs have been tested experimentally. The main focus was set to three points: how many semi-circular walls (semi-elliptic walls) are really necessary for evaporation and superheating, what is the influence of the position of these walls, and is there a connection between the steam temperature and the number and arrangements of walls?

Tab. 1: Experimental parameters used for evaporation and superheating with different geometries.

\begin{tabular}{|l|c|c|c|c|}
\hline $\begin{array}{l}\text { Water mass flow } \\
{\left[\mathrm{kg} \cdot \mathrm{h}^{-1}\right]}\end{array}$ & 0.3 & 0.5 & 0.7 & 1.0 \\
\hline $\begin{array}{l}\text { Heating surface } \\
\text { temperature }\left[{ }^{\circ} \mathrm{C}\right]\end{array}$ & 130 & 140 & 155 & 170 \\
\hline $\begin{array}{l}\text { applied electrical } \\
\text { power } \\
{[\mathrm{W}]}\end{array}$ & 254 & 407 & 560 & 820 \\
$\begin{array}{l}\text { evaporation power } \\
{[\mathrm{W}]}\end{array}$ & 190 & 306 & 430 & 600 \\
\hline
\end{tabular}

It was experimentally shown that it is possible to generate superheated steam with a single sidewall around a circular or elliptic blank, if it is arranged at the outermost circumference of the microstructure inlay. A single circular blank with sidewalls arranged directly around the water inlet will lead to complete evaporation, but almost no superheating is possible with this arrangement. Results of further experiments are given in Fig. 11 and Fig. 12. Here, the outlet steam temperature is plotted against time for complete evaporation. This plot style was 
chosen to show the transient behaviour of superheating. In all experiments the flow velocity of the steam was increased drastically due to an increase in volume by the evaporation inside the circular blanks. Maximum flow velocity and maximum superheating temperature are coincident, which is shown in both figures Fig. 11 and Fig. 12 by reaching the saturation.

Fig. 11 shows the outlet steam temperature obtained with the same water mass flow of $0.7 \mathrm{~kg} \cdot \mathrm{h}^{-1}$ and the same electrical power. It is clear shown that evaporation and superheating can be obtained with the sidewalls arranged at the outer limit of the circular blank, but not with those arranged at the inner limit.

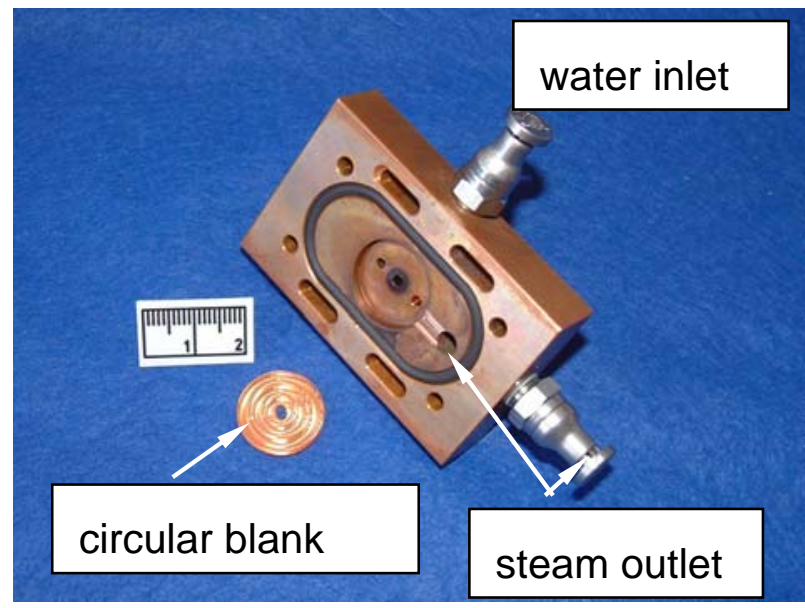

Fig. 10: Test adapter system to house copper circular blanks.

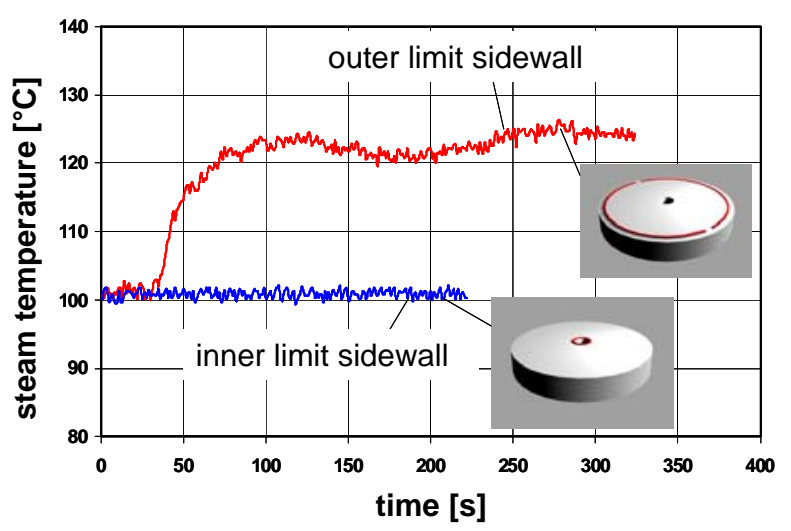

Fig. 11: Results obtained with two different sidewall arrangements, obtained with the same electrical power and water mass flow. It is clearly to see that only the arrangement of sidewalls at the outer limits of the circular blank leads to steam superheating.
More experiments showed that the number of sidewalls or structures inside the outer limits of the circular blanks influences the exit temperature of the steam. At the same water mass flow of $1.0 \mathrm{~kg} \cdot \mathrm{h}^{-1}$ and the same electrical power applied three different arrangements have been tested for their capability to generate superheated steam. It was shown that a slight superheating was possible with a single sidewall arrangement at the outer limits. Higher temperatures have been obtained when several inner sidewalls or structures have been used. The same results have been obtained with circular sidewalls, as it is shown in Fig. 12. Similar results have been obtained with elliptic sidewalls.

The plots in Fig. 12 show that the steam temperature is decreasing with decreasing number of sidewalls, and that steam superheating is slightly possible with a single sidewall arrangement at the outer blank limit. No higher temperature is possible, no matter what electrical power is applied. This can partly be explained by an increase of

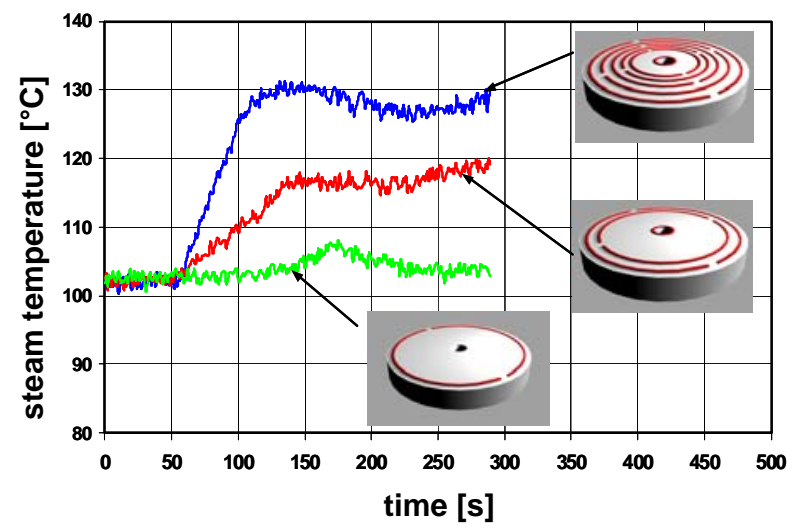

Fig. 12: steam outlet temperature obtained with different numbers of sidewalls.

evaporation pressure to the larger numbers of circular blanks, but the pressure difference between the two structures used for the red and the blue plot are within measurement uncertainty. Thus, more experiments have to be performed to clarify the influence of pressure inside the circular blanks. However, the temperature shown in Fig. 12 was measured at ambient pressure.

The plots shown in Fig. 11 have been obtained with a lower water mass flow of 
$0.7 \mathrm{~kg} \cdot \mathrm{h}^{-1}$. Thus, a mass flow limit for the use of a single sidewall arrangement for superheating seems to be somewhere in between $0.7 \mathrm{~kg} \cdot \mathrm{h}^{-1}$ and $1.0 \mathrm{~kg} \cdot \mathrm{h}^{-1}$. According to this finding, an optimum design in terms of evaporation, superheating temperature and pressure drop can probably be defined for every mass flow range. However, more work has to be done in future to find this optimum and to define perhaps a theoretical model description which allows a pre-calculation of the design.

\section{Summary}

Several metallic microstructure devices with multi-micro channel array arrangements for evaporation of liquids, especially water, have been designed, manufactured and tested. Fluid driven devices in crossflow and countercurrent or co-current design are quite limited in temperature, while electrically powered devices are much more flexible to use. A special device was generated to allow optical inspection of the evaporation process through a glass lid by high speed videography. Several evaporation effects like micro channel plugging have been visualized, and different designs of the inlet for flow distribution into the micro channel array have been tested. It was found that long straight micro channels are not optimal for evaporation. Thus, a new design based on circular blanks including numerous circular or elliptic sidewalls at different positions have been tested. It was shown that full evaporation and superheating could be obtained with a single side wall at the outer limit. This arrangement is only suitable for a certain mass flow range, as it was shown. Further investigations will be done to optimize the performance and to allow a pre-calculation of the design to the desired mass flow as well as to the superheating temperature.

\section{References}

[1] Brandner, J.J., Micro Process Engineering: Aspects of Miniaturization for a New Technology, Habilitation Thesis, Technical University of Dresden, 2008
[2] Brandner, J.J., T. Gietzelt, T. Henning, M. Kraut, H. Moritz and W. Pfleging, Micro Process Engineering Sec. 10: Microfabrication in Metals and Polymers. Advanced Micro \& Nanosystems (O. Brand, G.K. Fedder, C. Hierold, J.G. Korvik, O. Tabata, (Eds.) and N. Kockmann (Volume Ed.)), Wiley-VCH, Weinheim, Germany, 2006, 267-319

[3] Schubert, K., J.J. Brandner, M. Fichtner, G. Lindner, U. Schygulla and A. Wenka, Microstructure Devices for Applications in Thermal and Chemical Process Engineering. Microscale Thermophysical Engineering, Vol. 5 No. 1, 2001, 17-39

[4] Goedde, M., Liebner, C., Hieronymus, H., Sicherheit in der Mikroreaktionstechnik, Chemie Ingenieur Technik, 1-2, 2009, 73-78

[5] Brandner, J.J., E. Anurjew, L. Bohn, E. Hansjosten, T. Henning, U. Schygulla, A. Wenka and K. Schubert, Concepts and Realization of Microstructure Heat Exchangers for Enhanced Heat Transfer. Experimental Thermal and Fluid Science, Vol. 30, 2006, 801-809

[6] Thome, J.R., State-of-the-Art of Boiling and Two-Phase Flows in Microchannels, Heat Transfer Engineering, 27(9), 2006, 4-19

[7] Henning, T., Brandner, J.J., Schubert, K., Characterisation of electrically powered micro heat exchangers, Chemical Engineering Journal 101/1-3, 2004, 339-345

[8] Henning, T., Brandner, J.J., Schubert, K., Lorenzini, M. and Morini, G.L., LowFrequency Instabilities in the Operation of Metallic Multi-Microchannel Evaporators. Heat Transfer Engineering, Vol. 28, No. 10, 2007, 834-841

[9] Knauss, R., Marr, R., Brandstätter, R., Dynamic Optimization of an Evaporator by a Nonlinear Model Predictive Controller for Operation at modular Micro Rectification, Proc. Int. Symposium on Micro Chemical Process and Synthesis MIPS2009, Sep 11-13, 2009, Kyoto, Japan, 108-111

[10] Vittoriosi, A., Characterization of Microstructure Evaporators using Optical Measurements, Diploma Thesis, Forschungszentrum Karlsruhe, IMVT, Universita di Bologna, 2009

[11] Bauer, T., Experimental and theoretical 
investigations of monolithic reactors for threephase catalytic reactions, $\mathrm{PhD}$ thesis. Faculty of Mechanical Engineering, Dresden Univesity of Technology, 2007

[12] Cortina Diaz, M., Flow boiling heat transfer in narrow channels, $\mathrm{PhD}$ thesis, University of Magdeburg, Faculty of Process and System Technology, 2008

[13] Chen, W.L., Twu M.C., Pan, C., Gasliquid two-phase flow in micro-channels. International Journal of Multiphase Flow, Vol. 28, 2002, 1235-1247.

[14] Coleman, J.W., Garimella, S., Characterization of two-phase flow patterns in small diameter round and rectangular tubes. International Journal of Heat and Mass Transfer, Vol. 42, 1999, 2869-2881.
[15] Cubaud, T., Ho, C.-M., Transport of bubbles in square microchannels. Physics of Fluids, Vol. 16, 2004, 4575-4585.

[16] Henning, T., Brandner, J.J., Schubert, K., High-Speed Imaging of Flow in Microchannel Array Evaporators. Microfluidics and Nanofluidics, Vol. 1, 2007, 128-136.

[17] Bosnjakovic, F., Technische Thermodynamik Teil 1, 8. corr. ed., Steinkopf Darmstadt, Germany, 1998

[18] Brandner, J.J., Anurjew, E., Hansjosten, E., Pfleging, W., Schubert, K., Microstructure device generation by selective laser melting, Proc. SPIE Photonics West, San Jose, CA, USA, Jan 25-27, 2007 